\title{
Motion Deixis, Indexicality, and Presupposition
}

\author{
David Y. Oshima \\ Stanford University
}

\section{Introduction}

This paper argues that deictic verbs GO and COME (English go and come and their counterparts in other languages) are kinds of indexicals in the Kaplanian sense. In Sections 2-3, building on Oshima (2006a), I defend the view that the acceptability of deictic verbs is determined with respect to a contextually provided set of individuals (rather than with respect to a specific individual that serves as the "deictic center"), and demonstrate that the pragmatic meanings associated with deictic verbs are both presuppositional and indexical.

In Sections 4-6, I address the "deictic perspective shift" phenomenon in attitude reports, and argue that GO/COME can be used either as primary indexicals (which refer to the external context of utterance) or as secondary indexicals (which refer to a secondary context associated with an attitude predicate). Also, I demonstrate that the choice of the deictic perspective has interesting correlations with projection patterns of presuppositions associated with deictic verbs.

In Sections 7-9, I develop an analysis of attitude reports where a presupposition may be filtered by an attitude predicate (in accordance with Heim 1992 and Karttunen 1974), or may be inherited through it. The proposed analysis provides a solution to the more general (and long-standing) problem for the theory of presupposition projection, which has been known as "de re presuppositions".

\section{The Set-based Analysis of GO and COME}

As the background theory of motion deixis, I adopt the "set-based" analysis proposed by Oshima (2006a). Its essential idea is that deictic verbs make reference to a set of individuals called $R P$ (which stands for "Reference Point") and their meanings involve an existential statement or the negation of an existential statement; i.e.:

(1) a. GO requires that no member of the RP be located at the goal of the described motion.

b. COME requires that some member of the RP be located at the goal of the described motion.

Cross-linguistic differences among motion deictic systems can be sorted out into two dimensions. First, different languages are subject to different sets of

Thanks to Christopher Tancredi, David Beaver, Stanley Peters, Ivan Sag, Tsuneko Nakazawa, and the audience of SALT XVI for valuable comments and help. Any remaining errors are my own. 
person-based restrictions as to what can or must be a member of the RP. In English, for example:

(2) a. The speaker is always a member of the RP.

b. In many situations, it is preferred for the addressee to be a member of the $\mathrm{RP}$ as well.

c. A third person entity can be chosen as a member of the RP if it is discoursesalient. Inclusion of a non-SAP entity is marginal, however, when the speaker or the addressee is the theme (the moving entity) (or, when the theme is a group, a member thereof).

Thus, in English, typically the RP $=\{$ the speaker, the addressee $\}$.

Second, particular instances of deictic verbs may differ from one another as to which lower stretch of the following hierarchy they make reference to.

an RP member's location at the utterance time $<$ an RP member's location at the event time $<$ an RP member's "home base" (at the event time)

For example, in English, go refers to the utterance time only, while come refers to the utterance time, the event time, and RP members' home bases. This, in conjunction with (1), amounts to the following:

(4) a. Go requires that no member of the RP be at the goal at the utterance time.

b. Come requires that (i) there be some member of the RP at the goal at the utterance time or at the event time, or (ii) the goal be the home base of a member of the RP (at the event time).

The set-based analysis makes correct predictions on data like the following: ${ }^{1}$

(5) Will you $\left\{{ }^{*} \mathrm{go} /\right.$ come $\}$ visit me?

(The speaker must be a member of the RP.)

(6) Can I $\{$ ??go/come $\}$ visit you?

(It is preferred for the addressee to be a member of the RP.)

(7) a. John should $\{$ go/come $\}$ to talk to Prof. Yamada.

b. I should $\{\mathrm{go} /$ ??come $\}$ to talk to Prof. Yamada.

(Inclusion of a third person entity in the RP is marginal when the speaker is the theme.)

The pragmatic meanings encoded by GO and COME satisfy the standard criteria for presuppositions. First, they survive under negation; e.g. (8a) and (8b) both entail (roughly) that the speaker or the addressee is or was in New York.

(8) a. John came to New York.

\footnotetext{
${ }^{1}$ Advantages of the set-based analysis over its alternatives, such as those proposed by Fillmore (1997) and Talmy (2000), are discussed in detail in Oshima (2006a,b).
} 


\section{b. John didn't come to New York.}

Also, when a clause containing a deictic verb is embedded as a consequent of a conditional, the whole sentence does not (necessarily) inherit the relevant entailment; this projection pattern too suggests that the pragmatic entailment associated with a deictic verb is a presupposition. ${ }^{2}$

(9) If I had been in San Jose, John would have come (there), too.

ps: The speres or the

\section{GO/COME as Indexicals}

The meanings of deictic verbs are context-sensitive in the sense that they refer to the contextually determined RP. I propose to treat the RP as a component of the context of utterance in the Kaplanian sense and to add the coordinate of RP to the context tuple, so that it looks like: 〈agent, (addressee,) time, place, RP $\rangle$. Accordingly, deictic predicates can be treated as kinds of indexical expressions (on a par with first person pronouns, etc.), in the sense that their meanings (contents) are contingent on the context of utterance.

The following example, which contains three indexicals ( $I$, the past tense, and here) illustrates the general treatment of indexicals I adopt in the present work (an extensional logic with world variables, instead of a modal/tense logic, is used as the meaning language):

$$
\begin{aligned}
& \text { I danced here } \mapsto \lambda w_{1}\left[\exists e _ { 1 } \left[\operatorname{dance}\left(w_{1}, e_{1}, \mathbf{A g}(c *)\right) \wedge\right.\right. \\
& \left.\left.\operatorname{T-loc}\left(w_{1}, e_{1}\right)<\operatorname{Time}(c *) \wedge \mathbf{S}-\operatorname{loc}\left(w_{1}, e_{1}\right)=\operatorname{Place}(c *)\right]\right]
\end{aligned}
$$

where $^{3}$
a. $\llbracket \operatorname{Ag}(c) \rrbracket^{\mathrm{c}, \mathrm{w}, \mathrm{g}}=$ the agent coordinate of $\llbracket c \rrbracket^{\mathrm{c}, \mathrm{w}, \mathrm{g}}$
b. $\llbracket$ Time $(c) \rrbracket^{\mathrm{c}, \mathrm{w}, \mathrm{g}}=$ the time coordinate of $\llbracket c \rrbracket^{\mathrm{c}, \mathrm{w}, \mathrm{g}}$
c. $\llbracket$ Place $(c) \rrbracket^{\mathrm{c}, \mathrm{w}, \mathrm{g}}=$ the place coordinate of $\llbracket c \rrbracket^{\mathrm{c}, \mathrm{w}, \mathrm{g}}$
d. $\llbracket \mathbf{R P}(c) \rrbracket^{\mathrm{c}, \mathrm{w}, \mathrm{g}}=$ the RP coordinate of $\llbracket c \rrbracket^{\mathrm{c}, \mathrm{w}, \mathrm{g}}$
a. $\llbracket \mathbf{T}-\operatorname{loc}(e, w) \rrbracket^{\mathrm{c}, \mathrm{w}, \mathrm{g}}=$ the temporal location of $\llbracket e \rrbracket^{\mathrm{c}, \mathrm{w}, \mathrm{g}}$ in $\llbracket w \rrbracket^{\mathrm{c}, \mathrm{w}, \mathrm{g}}$
b. $\llbracket \mathbf{S}-\operatorname{loc}(e, w) \rrbracket^{\mathrm{c}, \mathrm{w}, \mathrm{g}}=$ the spatial location of $\llbracket e \rrbracket^{\mathrm{c}, \mathrm{w}, \mathrm{g}}$ in $\llbracket w \rrbracket^{\mathrm{c}, \mathrm{w}, \mathrm{g}}$

and

${ }^{2}$ This contrasts with, for example, the case of a gender requirement posed by a pronoun:

(i) If Chris i $_{i}$ takes this magic potion which turns any man or woman into a beautiful girl, many boys will be attracted to her . $_{\text {. }}$

entailment: Chris is female (regardless of whether she takes the potion).

${ }^{3}$ N.B.: $\llbracket \alpha \rrbracket^{\mathrm{c}, \mathrm{w}, \mathrm{g}}=$ the value of $\alpha$ with respect to context $\mathrm{c}$, world w, and assignment $\mathrm{g}$. 
a. $\llbracket c * \rrbracket^{\mathrm{c}, \mathrm{w}, \mathrm{g}}$ is defined only if $\mathrm{g}(c *)=\mathrm{c}$. If defined $\llbracket c * \rrbracket^{\mathrm{c}, \mathrm{w}, \mathrm{g}}=\mathrm{g}(c *)$.

(In other words, $c *$ is a special variable that is always mapped the external context of utterance.)

b. $\llbracket c_{i} \rrbracket^{\mathrm{c}, \mathrm{w}, \mathrm{g}}=\mathrm{g}\left(c_{i}\right)$.

The meanings of sentences involving go and come can be approximated using the logical connective called prejunction (Blau's 1985 term; the definition follows):

a. John went to San Jose $\mapsto$

$\lambda w_{1}\left[\exists e_{1}\left[\left[\operatorname{move-to}\left(w_{1}, e_{1}, \mathbf{j o h n}, \mathbf{s . j}.\right) \wedge \operatorname{T-loc}\left(w_{1}, e_{1}\right)<\operatorname{Time}(c *)\right] /\right.\right.$

$\neg \exists y\left[y \in \mathbf{R P}(c *) \wedge \exists e_{2}\left[\operatorname{at}\left(w_{1}, e_{2}, y, \mathbf{s . j}.\right) \wedge \mathbf{T}-\operatorname{loc}\left(w_{1}, e_{2}\right) \supseteq\right.\right.$

$\operatorname{Time}(c *)]]]]$

b. John came to San Jose $\mapsto$

$\lambda w_{1}\left[\exists e_{1}\left[\left[\operatorname{move}-\mathbf{t o}\left(w_{1}, e_{1}, \mathbf{j o h n}, \mathbf{s . j} . \mathbf{j}\right) \wedge \operatorname{T}-\operatorname{loc}\left(w_{1}, e_{1}\right)<\operatorname{Time}(c *)\right] /\right.\right.$

$\exists y\left[y \in \mathbf{R P}(c *) \wedge\left[\exists e_{2}\left[\operatorname{at}\left(w_{1}, e_{2}, y, \mathbf{s . j}.\right) \wedge\left[\mathbf{T}-\operatorname{loc}\left(w_{1}, e_{2}\right) \supseteq \operatorname{Time}(c *) \vee\right.\right.\right.\right.$

$\left.\left.\mathbf{T C}\left(w_{1}, e_{1}, e_{2}\right)\right]\right] \vee \exists e_{3}\left[\operatorname{home-base}\left(w_{1}, e_{3}, \mathbf{j o h n}, \mathbf{s . j}.\right) \wedge\right.$

$\left.\left.\left.\left.\left.\mathbf{T C}\left(w_{1}, e_{1}, e_{3}\right)\right]\right]\right]\right]\right]$

where

(15) prejunction

$\llbracket \phi / \psi \rrbracket^{\mathrm{w}, \mathrm{c}, \mathrm{g}}$ is defined only if $\llbracket \psi \rrbracket^{\mathrm{w}, \mathrm{c}, \mathrm{g}}=1$. If defined, $\llbracket \phi / \psi \rrbracket^{\mathrm{w}, \mathrm{c}, \mathrm{g}}=\llbracket \phi \rrbracket^{\mathrm{w}, \mathrm{c}, \mathrm{g}}$.

(16) $\quad \llbracket \mathbf{T}($ emporal $) \mathbf{C}($ oincidence $)\left(w, e_{1}, e_{2}\right) \rrbracket^{\mathrm{c}, \mathrm{w}, \mathrm{g}}$

$=1$ iff $\llbracket e_{1} \rrbracket^{\mathrm{c}, \mathrm{w}, \mathrm{g}}$ and $\llbracket e_{2} \rrbracket^{\mathrm{c}, \mathrm{w}, \mathrm{g}}$ temporally overlap in $\llbracket w \rrbracket^{\mathrm{c}, \mathrm{w}, \mathrm{g}}$

$=0$ otherwise

\section{4. "Deictic Perspective Shift" in Reported Discourse}

In past studies, several authors have pointed out that in an attitude report the choice between go/come can be made with respect to either the primary (external) speaker's perspective or the secondary (reported) agent's (Hockett 1990, Kuno 1988, Oe 1975). The following examples illustrate this point (assume that the following sentences are all uttered in a situation where the addressee is not at the goal either at the utterance time or at the event time):

(17) [Situation: The speaker and the addressee are in Los Angeles; John is in New York now, and will be there in two weeks too.]

a. John believes that I will go to New York in two weeks.

b. John believes that I will come to New York in two weeks.

cf. ??I will come to New York in two weeks.

(18) [Situation: The speaker and the addressee are in the same place.]

a. John claims that I should go to give him a hand. 
b. John claims that I should come to give him a hand.

cf. ?*I should come to give John a hand.

(19) [Situation: The speaker and the addressee are in Los Angeles, and will be there on Thursday too; John is in New York.]

a. John said that he would come to Los Angeles on Thursday.

b. John said that he would go to Los Angeles on Thursday.

cf. ??John will go to Los Angeles on Thursday.

(20) [Situation: The speaker and the addressee are in the same place. The speaker is in the same place as he was a week ago.]

a. John believes that his brother came to give me a hand a week ago.

b. John believes that his brother went to give me a hand a week ago.

cf. ?*John's brother went to give me a hand a week ago.

In the complement clauses of (17b), (18b), (19b), and (20b), the choice of the deictic verb does not conform to the restrictions on the RP presented above. To explain the acceptability of these sentences, it seems reasonable to hypothesize that in an indirect quote the selection of the members of RP can be made from the secondary agent's perspective, rather than from the external speaker's. ${ }^{4}$

In the following two sections, we will observe that (i) the deictic perspective shift phenomenon has interesting correlations with presupposition projection, and (ii) the choice of the deictic perspective also directly corresponds to the de se/nonde se opposition with respect to motion deixis.

\footnotetext{
${ }^{4}$ Under certain conditions, configurations like "[1st person] comes to [3rd person]" and "[3rd person] goes to [1st person]" seem not to be entirely blocked in non-report environments (e.g., adverbial clauses), either:

(i) a. John may be fired from his job if I don't $\{$ go/?come $\}$ to give him a hand.

b. Ken will be able to finish the assignment by Friday if he $\{? ? \sim$ ? goes/comes $\}$ to consult me.

Based on such observations, one may suspect that the "deictic perspective shift" phenomenon is not peculiar to attitude report environments. There are two reasons, however, to believe that this is not the case. First, the acceptability of the marked patterns is generally higher in complement clauses of attitude predicates than in adjunct clauses (see Oshima 2006b for a survey). Second, the deictic perspective shift in attitude reports is not only relevant to the acceptability of the use of GO/COME, but it also has correlations with the level to which presuppositions triggered by $\mathrm{GO} / \mathrm{COME}$ are projected, and this phenomenon cannot be explained by simply manipulating the licensing conditions of GO/COME (see below).
} 


\section{Projection of Presuppositions Triggered by Deictic Verbs}

\subsection{Primary Deictic Perspective and Attitude Predicates as Holes}

It has been commonly believed that presuppositions in attitude report environments are filtered by (non-factive) attitude predicates like believe (Karttunen 1974, Heim 1992 ), i.e., " $\alpha$ believes $\phi$ " does not presuppose $\mathbf{p s}(\phi)$ (the presupposition of $\phi$ ), but only ' $\alpha$ believes $\mathbf{p s}(\phi)$ ' (this view, however, will be questioned shortly). ${ }^{5}$ The following example illustrates this point:

(21) John believes that Linda stopped smoking.

presupposes: John believes that Linda used to smoke.

does not presuppose: Linda used to smoke.

(22) John believes that Linda would smoke when she was a college student. He also believes that she already stopped smoking.

This projection pattern, however, does not hold for presuppositions induced by deictic predicates, when the deictic perspective is anchored to the primary (external) speaker. Consider the following example:

(23) [Situation: John is speaking to Linda. Bob has been in New York for a month, and John believes that (Bob believes that) Bob has been in New York for a month.]

John: "Bob believes that Chris came to San Jose two weeks ago."

The RP adopted by John (in the external context of utterance) is likely to be: $\{$ John, Linda\}, while the one adopted by Bob (in the context of the reported belief) is likely to be: $\{$ Bob $\} .{ }^{6}$ Thus, in the described situation, the utterance above naturally receives the "primary" interpretation, in which case the presupposition of the complement clause is roughly equivalent to:

(24) John or Linda is in San Jose at the utterance time or was there at the event time (two weeks ago).

Crucially, this presupposition is a presupposition of the whole sentence as well (i.e., is projected to the matrix level). That is, (23) presupposes (24), rather than something like:

(25) Bob believes that John or Linda is in San Jose at the utterance time or was there at the event time.

\footnotetext{
${ }^{5}$ Speech predicates like say have a different heritage property, i.e., they can "plug", rather than "filter", presuppositions under their scope (and under certain conditions, they can also pass up presuppositions under their scope like mental attitude predicates like believe; see below) (Oshima 2006b). Due to space limitation, I will not consider them in the present work.

${ }^{6}$ Throughout the rest of the paper, I will assume that the RP adopted by the speaker of an utterance is: $\{$ the speaker, the addressee $\}$, and that the RP adopted by the agent of a reported attitude is: \{the agent $\}$.
} 
It is easy to confirm that (23) does not presuppose (25) on the interpretation in question; Bob's belief about the location of John or Linda is clearly irrelevant for the felicity of (23) (Bob does not need to have any belief or knowledge concerning John or Linda, for that matter).

\subsection{Secondary Deictic Perspective and Attitude Predicates as Filters}

Next let us consider a case where the deictic perspective is anchored to the secondary agent.

(26) [Situation: John is speaking to Linda; they have been in New York for a month.]

John: "Bob believes that Chris came to San Jose two weeks ago."

In the described situation, neither the external speaker nor the external addressee is at the goal, and thus the utterance naturally receives the secondary interpretation. The presupposition of the complement clause is then roughly equivalent to:

(27) Bob is in San Jose at the utterance time or was there at the event time (two weeks ago).

This time, importantly, the presupposition is not projected to the matrix level, in accordance with observations/predictions by Heim (1992) and Karttunen (1974). What (26) presupposes is something like (28), but not (27). This can be confirmed by observing a discourse like (29).

(28) Bob believes that he is in San Jose at the utterance time or was there at the event time.

(29) Bob (wrongly) believes that he has been in San Jose for a month, and he also believes that Chris came there two weeks ago.

In sum, presuppositions triggered by GO and COME are passed up through an attitude predicate when the deictic perspective is anchored to the external speaker, while they are filtered when the deictic perspective is anchored to the secondary agent.

\section{The $\mathrm{De} S \mathrm{Se} / \mathrm{Non}-\mathrm{De} \mathrm{Se}$ Distinction with respect to Motion Deixis}

The opposition of the primary/secondary deictic perspectives has a direct correspondence to the opposition of the non-de selde se modes of attitude reports. That is, a report from the primary perspective is a report that is non-de se with respect to motion deixis, where (part of) the deictic information in the "original" (reported) attitude (belief, etc.) is lost; a report from the secondary perspective, on the other hand, is a report that is de se with respect to motion deixis, where such information is maintained. 
To illustrate this point clearly, let us first observe an example of the de se/non-de se alternation with respect to a context coordinate other than the RP. Attitude predicates in Japanese allow either the de se or non-de se modes with respect to the agent coordinate, i.e., a report of an attitude about the secondary agent can be made either with a secondary indexical zibun or with a regular third person pronoun kare, etc. (Oshima 2006b).

$$
\begin{aligned}
& \text { a. } \text { John }_{i} \text {-wa [zibun }{ }_{i} \text {-ga boku-o tasuke-ta] to omotte-i-ru. } \\
& \text { John-Top self-Nom I-Acc help-Past Comp believe-Asp-Pres } \\
& \text { ' } \mathrm{John}_{i} \text { believes that he* }{ }_{i} \text { helped me.' } \\
& \text { (N.B.: } h e^{*} \text { is an artificial logophoric pronoun; cf. Schlenker 2003) } \\
& \text { b. John }{ }_{i} \text {-wa [ } \text { kare }_{i} \text {-ga boku-o tasuke-ta] to omotte-i-ru. } \\
& \text { John-Top he-Nom I-Acc help-Past Comp believe-Asp-Pres } \\
& \text { 'John }{ }_{i} \text { believes that he }{ }_{i} \text { helped me.' }
\end{aligned}
$$

(30a) in the de se mode is compatible only with Situation 1 in (31), while (30b) is compatible either with Situation 1 or 2; in other words, the contrast between 'I' and 'he' in the original belief is lost in (30b).

[David $=$ the external speaker of (30)]

Situation 1: John believes: "I helped David".

Situation 2: After reading his own biography, amnesic John has come to believe: "This guy called John helped David".

Now consider the following report where the deictic perspective is anchored to the primary agent and the presupposition triggered by the deictic predicate is passed up to the matrix level:

(32) John: "Bob believes that Chris came to San Jose." (primary perspective) ps: John (or the addressee) is in San Jose at the utterance time or was there at the event time.

Such a sentence does not capture (a certain portion of) the deictic information in the original belief. Recall that we decided to treat deictic predicates as indexicals; this means that a pair of the form: " $\alpha$ goes to $\beta$ "/" $\alpha$ comes to $\beta$ " can, analogous to a pair like "I helped David"/"He helped David", be equivalent in their content, but not in their character. From (32), we cannot infer what propositional character exactly John's "original" belief corresponded to. It could have been "Chris came to San Jose', but it could as well have been 'Chris went to San Jose' or 'Chris moved to San Jose'. In other words, the contrast between go, come, and move in the original belief is lost in the report; in this sense, such a report is non-de se with respect to motion deixis.

In contrast, when the deictic perspective in an indirect report is anchored to the secondary agent, the deictic information in the original belief is maintained. The following attitude report, for example, reflects that Bob's belief was 'Chris came to San Jose', rather than 'Chris went to San Jose', etc.: 
John: "Bob believes that Chris came to San Jose." (secondary perspective) ps: Bob believes that he is in San Jose at the time of "believing" or was there at the event time.

Such a report can be understood as de se with respect to motion deixis; also, an occurrence of GO or COME in (the complement clause of) an attitude report from the secondary perspective can be treated as an instance of secondary indexical on a par with Japanese zibun (in its logophoric use), a logophoric pronoun, etc. (cf. Schlenker 2003).

\section{Questioning the Common View: Is an Attitude Predicate a Filter or a Hole?}

The observations in Section 5 lead us to question the commonly accepted view that attitude predicates are invariably filters, and suspect that they can pass up presuppositions within their scope under certain conditions. After all, data like (22) merely prove that " $\alpha \nu$ 's $\phi$ " (where $v$ is an attitude predicate) does not necessarily presuppose $\mathbf{p s}(\phi)$. There have been, on the other hand, occasional remarks in the literature that " $\alpha$ believes $\phi$ " indeed may presuppose $\mathbf{p s}(\phi)$ (Zeevat 1992, Beaver and Zeevat 2004; cf. Heim 1992: 211-2). Consider the following example:

(34) John believes that even [Mary $]_{\mathrm{F}}$ escaped.

On one reading, (34) presupposes that John believes that Mary was the least likely person to escape; on this reading, the attitude predicate serves as a filter. On another reading, the ps trigger even takes the matrix scope, so that the presupposition of the whole sentence is something like 'Mary is the least likely person to be believed by John to have escaped'; this reading is irrelevant to our present discussion. Now, it appears that (34) has yet another reading, on which it presupposes that Mary was actually the least likely person to escape, while John may or may not believe that Mary was unlikely to escape.

a. ps on the "narrow scope" reading: John believes that Mary was the least likely person to escape. (In actuality, Mary may or may not have been the least likely person to escape.)

b. ps on the "wide scope" reading: Mary is the least likely person to be believed by John to have escaped.

c. ps on the "de re-like" reading: Mary was actually the least likely person to escape. (John may or may not believe that Mary was the least likely person to escape.)

The judgment is quite subtle, but I believe that the third reading is real. This observation suggests that the correct generalization about the heritage property (in the sense of Heim 1983) of attitude predicates is the following:

(36) " $\alpha v$ 's $\phi$ ", where $v$ is an attitude predicate like believe, hope, .., presupposes either ' $\mathbf{p s}(\phi)$ ' or ' $\alpha$ believes $\mathbf{p s}(\phi)$ '. 
In other words, attitude predicates in general are ambiguous between their "hole" and "filter" interpretations.

Under this new assumption, it is not necessary to give presuppositions associated with deictic verbs a special treatment. In a report where the deictic perspective is anchored to the primary agent, the attitude predicate behaves as a hole; when it is anchored to the secondary agent, on the other hand, the attitude predicate behaves as a filter.

As the reader may have noticed, the formulation in (36) makes the following prediction:

(37) Multiple ps's triggered in the complement clause of an attitude report are either uniformly filtered by the attitude predicate, or uniformly passed up.

To give a concrete example, it is predicted that (38) presupposes that either (i) (39a-i) and (39b-i) hold, or (ii) (39a-ii) and (39b-ii) hold:

(38) John believes that Linda will manage to come to his room.

(39) a. i. It is difficult to get to John's room.

ii. John believes that it is difficult to get to his room.

b. i. The speaker or the addressee is or will be in John's room.

ii. John believes that he is or will be in his room.

The following discourse sounds felicitous, as it should, (39a-ii) and (39b-ii) being satisfied.

(40) [Situation: John is staying at a hotel room, and neither the speaker nor the addressee is in John's room.]

Being paranoiac, John believes that the hotel he is staying at is a securely guarded fortress. John believes, however, that Linda will manage to come to his room.

Now consider (41), where come is replaced with go. Analogous to the case of (38), this sentence presupposes that either (i) (42a-i) and (42b-i) hold or (ii) (42a-ii) and (42b-ii) hold:

(41) John believes that Linda will manage to go to his room.

(42) a. i. It is difficult to get to John's room.

ii. John believes that it is difficult to get to his room.

b. i. Neither the speaker nor the addressee is in John's room.

ii. John believes that he is not in his room.

The following discourse sounds awkward/infelicitous; again this is as it should be, as in the described situation only (42-aii) and (42b-i) (but not 42a-i or 42b-ii) are satisfied. 
(43) [Situation: John is staying at a hotel room, and neither the speaker nor the addressee is in the same room.]

Being paranoiac, John believes that the hotel he is staying at is a securely guarded fortress. ??John believes, however, that Linda will manage to go to his room. (cf. $\sqrt{ }$ John believes, however, that Linda will go to his room.)

These observations suggest that the prediction in (37) is indeed correct. ${ }^{7}$

\section{The Multi-dimensional Approach to Presuppositions}

I adopt the multi-dimensional approach to presuppositions, where the dimensions of assertion and presupposition are separated, and a sentence is evaluated either as true/felicitous, false/felicitous, true/infelicitous, or false/infelicitous (Herzberger 1973, Bergmann 1981; cf. Karttunen and Peters 1979). More specifically, I postulate:

(44) $\quad \mathbf{D}_{t}$ (the interpretation domain for formulas) $=\wp(\{1,2\})$ (or in other words: $\mathbf{D}_{t}=\{\{1,2\},\{1\},\{2\}, \varnothing\}$ )

(45) Truth Definition: An expression $\lambda w_{1}[\phi]$ that serves as a translation of a natural language matrix sentence is, with respect to $\mathrm{c}, \mathrm{w}$, and $\mathrm{g}$,

a. true/felicitous ("True" for short) iff $\llbracket \phi \rrbracket^{\mathrm{c}, \mathrm{w}, \mathrm{g}\left[\mathrm{w} / w_{1}\right]}=\{1,2\}$

b. false/felicitous ("False" for short) iff $\llbracket \phi \rrbracket^{c, w, g}\left[\mathrm{w} / w_{1}\right]=\{2\}$

c. true/infelicitous ("True-ish" for short) iff $\llbracket \phi \rrbracket^{\mathrm{c}, \mathrm{w}, \mathrm{g}\left[\mathrm{w} / w_{1}\right]}=\{1\}$

d. false/infelicitous ("False-ish" for short) iff $\llbracket \phi \rrbracket^{\mathrm{c}, \mathrm{w}, \mathrm{g}\left[\mathrm{w} / w_{1}\right]}=\varnothing$

That is, value 1 and 2 concern the truth (satisfaction of the assertion) and the felicity (satisfaction of the presupposition) of a formula, respectively. It is assumed that predicate constants (such as laugh, student, and move-to) and set operators (as they are used in the meaning language) have, when applied to their arguments, either $\{1,2\}$ or $\{2\}$ as their value. lows: ${ }^{8}$

The standard operators/connectives in boolean systems are redefined as fol-

$$
\begin{aligned}
& \text { a. negation } \\
& 1 \in \llbracket \neg \phi \rrbracket^{\mathrm{c}, \mathrm{w}, \mathrm{g}} \text { iff } 1 \notin \llbracket \phi \rrbracket^{\mathrm{c}, \mathrm{w}, \mathrm{g}} ; \\
& 2 \in \llbracket \neg \phi \rrbracket^{\mathrm{c}, \mathrm{w}, \mathrm{g}} \text { iff } 2 \in \llbracket \phi \rrbracket^{\mathrm{c}, \mathrm{w}, \mathrm{g}}
\end{aligned}
$$

\footnotetext{
${ }^{7}$ This reasoning, of course, is valid only under the possibly simplistic assumption that a given occurrence of an operator (e.g., an attitude predicate, a connective) behaves either as a hole or filter (or plug) for all classes of ps's (including those triggered by deictic verbs, focus-sensitive particles like too, and factive predicates like regret) under its scope. This is an implicit assumption in most previous work on presupposition, and I maintain it in the present work too. It must be noted, however, that whether this uniformity assumption is valid is a matter of open debate (see Beaver and Zeevat 2004 for relevant discussion).

${ }^{8}$ The operators/connectives in (46a-g) are not proposed as translations or direct counterparts of not, and, all, etc. in natural language; see Oshima (2006b) for relevant discussion.
} 


\section{b. conjunction}

$1 \in \llbracket \phi \wedge \psi \rrbracket^{\mathrm{c}, \mathrm{w}, \mathrm{g}}$ iff $1 \in \llbracket \phi \rrbracket^{\mathrm{c}, \mathrm{w}, \mathrm{g}}$ and $1 \in \llbracket \psi \rrbracket^{\mathrm{c}, \mathrm{w}, \mathrm{g}}$;

$2 \in \llbracket \phi \wedge \psi \rrbracket^{\mathrm{c}, \mathrm{w}, \mathrm{g}}$ iff $2 \in \llbracket \phi \rrbracket^{\mathrm{c}, \mathrm{w}, \mathrm{g}}$ and $2 \in \llbracket \psi \rrbracket^{\mathrm{c}, \mathrm{w}, \mathrm{g}}$

c. disjunction

$1 \in \llbracket \phi \vee \psi \rrbracket^{\mathrm{c}, \mathrm{w}, \mathrm{g}}$ iff $1 \in \llbracket \phi \rrbracket^{\mathrm{c}, \mathrm{w}, \mathrm{g}}$ or $1 \in \llbracket \psi \rrbracket^{\mathrm{c}, \mathrm{w}, \mathrm{g}}$;

$2 \in \llbracket \phi \vee \psi \rrbracket^{\mathrm{c}, \mathrm{w}, \mathrm{g}}$ iff $2 \in \llbracket \phi \rrbracket^{\mathrm{c}, \mathrm{w}, \mathrm{g}}$ and $2 \in \llbracket \psi \rrbracket^{\mathrm{c}, \mathrm{w}, \mathrm{g}}$

\section{d. conditional}

$1 \in \llbracket \phi \rightarrow \psi \rrbracket^{\mathrm{c}, \mathrm{w}, \mathrm{g}}$ iff (i) $1 \notin \llbracket \phi \rrbracket^{\mathrm{c}, \mathrm{w}, \mathrm{g}}$ or (ii) $1 \in \llbracket \phi \rrbracket^{\mathrm{c}, \mathrm{w}, \mathrm{g}}$ and $1 \in \llbracket \psi \rrbracket^{\mathrm{c}, \mathrm{w}, \mathrm{g}}$;

$2 \in \llbracket \phi \rightarrow \psi \rrbracket^{\mathrm{c}, \mathrm{w}, \mathrm{g}}$ iff $2 \in \llbracket \phi \rrbracket^{\mathrm{c}, \mathrm{w}, \mathrm{g}}$ and $2 \in \llbracket \psi \rrbracket^{\mathrm{c}, \mathrm{w}, \mathrm{g}}$

\section{e. universal quantifier}

$1 \in \llbracket \forall \mathrm{v}_{\mathrm{a}} \phi \rrbracket^{\mathrm{c}, \mathrm{w}, \mathrm{g}}$ iff $1 \in \bigcap_{\mathrm{d} \in \mathbf{D}_{\mathrm{a}}}\left(\llbracket \phi \rrbracket^{\mathrm{c}, \mathrm{w}, \mathrm{g}[\mathrm{d} / \mathrm{v}]}\right) ;$

$2 \in \llbracket \forall \mathrm{v}_{\mathrm{a}} \phi \rrbracket^{\mathrm{c}, \mathrm{w}, \mathrm{g}}$ iff $2 \in \bigcap_{\mathrm{d} \in \mathbf{D}_{\mathrm{a}}\left(\llbracket \phi \rrbracket^{\mathrm{c}, \mathrm{w}, \mathrm{g}[\mathrm{d} / \mathrm{v}]}\right)}$

\section{f. existential quantifier}

$1 \in \llbracket \exists \mathrm{v}_{\mathrm{a}} \phi \rrbracket^{\mathrm{c}, \mathrm{w}, \mathrm{g}}$ iff $1 \in \bigcup_{\mathrm{d} \in \mathbf{D}_{\mathrm{a}}}\left(\llbracket \phi \rrbracket^{\mathrm{c}, \mathrm{w}, \mathrm{g}[\mathrm{d} / \mathrm{v}]}\right) ;$

$2 \in \llbracket \exists \mathrm{v}_{\mathrm{a}} \phi \rrbracket^{\mathrm{c}, \mathrm{w}, \mathrm{g}}$ iff $2 \in \bigcup_{\mathrm{d} \in \mathbf{D}_{\mathrm{a}}\left(\llbracket \phi \rrbracket^{\mathrm{c}, \mathrm{w}, \mathrm{g}[\mathrm{d} / \mathrm{v}]}\right)}$

\section{g. lambda operator}

$\llbracket \lambda v_{\mathrm{a}} \phi \rrbracket^{\mathrm{c}, \mathrm{w}, \mathrm{g}}=$ that function $\mathrm{f}$ such that for each $\mathrm{d} \in \mathbf{D}_{\mathrm{a}}, \mathrm{f}(\mathrm{d})=\llbracket \phi \rrbracket^{\mathrm{c}, \mathrm{w}, \mathrm{g}[\mathrm{d} / \mathrm{v}]}$

Furthermore, a new connective named preditional (a variant of Blau's "prejunction"/Blamey's "transplication") is introduced:

\section{preditional}

$1 \in \llbracket\langle\phi ; \psi\rangle \rrbracket^{\mathrm{c}, \mathrm{w}, \mathrm{g}}$ iff $1 \in \llbracket \phi \rrbracket^{\mathrm{c}, \mathrm{w}, \mathrm{g}} ;$

$2 \in \llbracket\langle\phi ; \psi\rangle \rrbracket^{\mathrm{c}, \mathrm{w}, \mathrm{g}}$ iff (i) $2 \in \llbracket \phi \rrbracket^{\mathrm{c}, \mathrm{w}, \mathrm{g}}$ and $2 \in \llbracket \psi \rrbracket^{\mathrm{c}, \mathrm{w}, \mathrm{g}}$ and (ii) $1 \in \llbracket \psi \rrbracket^{\mathrm{c}, \mathrm{w}, \mathrm{g}}$

A sentence associated with a presupposition can be given a proper logical form with this new connective. For example, "[John $]_{\mathrm{F}}$ laughed, too" (ps: Somebody other than John laughed) can be translated as (48) (the tense is ignored). ${ }^{9}$

$$
\lambda w_{1}\left[\exists e_{1}\left[\left\langle\operatorname{laugh}\left(w_{1}, e_{1}, \mathbf{j o h n}\right) ; \exists x_{1}\left[\exists e_{2}\left[x_{1} \neq \mathbf{j o h n} \wedge \operatorname{laugh}\left(w_{1}, e_{2}, x_{1}\right)\right]\right]\right\rangle\right]\right]
$$

As can be easily confirmed, (48) is evaluated as True-ish when John laughed and nobody other than John laughed, and as False-ish when nobody, including John, laughed.

To represent the heritage property of attitude predicates, the two operators defined below, which correspond to the $T$ and $\gamma$ operators in Bergmann's (1981) system, will come in handy:

a. assertion extractor (presupposition remover)

$\llbracket \operatorname{Conv}_{1}(\phi) \rrbracket^{\mathrm{c}, \mathrm{w}, \mathrm{g}}=\{1,2\}$ iff $1 \in \llbracket \phi \rrbracket^{\mathrm{c}, \mathrm{w}, \mathrm{g}} ;$

$\llbracket \operatorname{Conv}_{1}(\phi) \rrbracket^{\mathrm{c}, \mathrm{w}, \mathrm{g}}=\{2\}$ otherwise

\section{b. presupposition extractor (assertion remover)}

$\llbracket \operatorname{Conv}_{2}(\phi) \rrbracket^{\mathrm{c}, \mathrm{w}, \mathrm{g}}=\{1,2\}$ iff $2 \in \llbracket \phi \rrbracket^{\mathrm{c}, \mathrm{w}, \mathrm{g}} ;$

$\llbracket \operatorname{Conv}_{2}(\phi) \rrbracket^{\mathrm{c}, \mathrm{w}, \mathrm{g}}=\{2\}$ otherwise

\footnotetext{
${ }^{9}$ Here, I adopt the existential analysis of too along the lines of Kartunnen and Peters (1979); see van der Sandt and Geurts (2001) for an opposing view.
} 
Using Conv ${ }_{1}$ and $\mathbf{C o n v}_{2}$, we can "split" a single proposition (whose range is: $\{\{1,2\},\{1\},\{2\}, \varnothing\}$ ) into two propositions (whose range is: $\{\{1,2\},\{2\}\}$ ) which correspond to its asserted part and its presupposed part, respectively:

a. The assertion of ' $\mathrm{S}$ ', which denotes proposition $p$, can be expressed as: $\lambda w_{1}\left[\operatorname{Conv}_{1}\left(p\left(w_{1}\right)\right)\right]$

b. The presupposition of 'S', which denotes proposition $p$, can be expressed as: $\lambda w_{1}\left[\operatorname{Conv}_{2}\left(p\left(w_{1}\right)\right)\right]$

The lexical entries of go/come (as primary indexicals) can be given as follows:

$$
\begin{aligned}
& \text { a. go } \mapsto \lambda p l_{1}\left[\lambda x \left[\lambda e _ { 1 } \left[\lambda w _ { 1 } \left[\left\langle\text { move-to }\left(w_{1}, e_{1}, x, p l_{1}\right) ;\right.\right.\right.\right.\right. \\
& \neg \exists y\left[y \in \mathbf { R P } ( c * ) \wedge \exists e _ { 2 } \left[\mathbf{a t}\left(w_{1}, e_{2}, y, p l_{1}\right) \wedge\right.\right. \\
& \left.\left.\left.\left.\left.\left.\left.\quad \mathbf{T}-\mathbf{l o c}\left(w_{1}, e_{2}\right) \supseteq \operatorname{Time}(c *)\right]\right]\right\rangle\right]\right]\right]\right] \\
& \text { b. come } \mapsto \lambda p l_{1}\left[\lambda x \left[\lambda e _ { 1 } \left[\lambda w _ { 1 } \left[\left\langle\mathbf{m o v e}-\operatorname{to}\left(w_{1}, e_{1}, x, p l_{1}\right) ;\right.\right.\right.\right.\right. \\
& \quad \exists y\left[y \in \mathbf { R P } ( c * ) \wedge \left[\exists e _ { 2 } \left[\operatorname { a t } ( w _ { 1 } , e _ { 2 } , y , p l _ { 1 } ) \wedge \left[\mathbf{T}-\mathbf{l o c}\left(w_{1}, e_{2}\right) \supseteq \operatorname{Time}(c *)\right.\right.\right.\right. \\
& \left.\left.\quad \vee \mathbf{T C}\left(w_{1}, e_{1}, e_{2}\right)\right]\right] \vee \exists e_{3}\left[\operatorname{home-base}\left(w_{1}, e_{3}, x, p l_{1}\right) \wedge\right. \\
& \left.\left.\left.\left.\left.\left.\left.\quad \mathbf{T C}\left(w_{1}, e_{1}, e_{3}\right)\right]\right]\right\rangle\right]\right]\right]\right]
\end{aligned}
$$

For ease of presentation, in the following I will use the simplified representations given below, where temporal specifications as to RP members' presence at the goal and the reference to RP members' home bases are left out.

$$
\begin{aligned}
& \text { a. go } \mapsto \lambda p l_{1}\left[\lambda x \left[\lambda e _ { 1 } \left[\lambda w _ { 1 } \left[\left\langle\text { move-to }\left(w_{1}, e_{1}, x, p l_{1}\right) ;\right.\right.\right.\right.\right. \\
& \left.\left.\left.\left.\left.\neg \exists y\left[y \in \mathbf{R P}(c *) \wedge \exists e_{2}\left[\operatorname{at}\left(w_{1}, e_{2}, y, p l_{1}\right)\right]\right]\right\rangle\right]\right]\right]\right] \\
& \text { b. come } \mapsto \lambda p l_{1}\left[\lambda x \left[\lambda e _ { 1 } \left[\lambda w _ { 1 } \left[\left\langle\mathbf{m o v e}-\mathbf{t o}\left(w_{1}, e_{1}, x, p l_{1}\right) ;\right.\right.\right.\right.\right. \\
& \left.\left.\left.\left.\quad \exists y\left[y \in \mathbf{R P}(c *) \wedge \exists e_{2}\left[\mathbf{a t}\left(w_{1}, e_{2}, y, p l_{1}\right)\right]\right]\right\rangle\right]\right]\right]
\end{aligned}
$$

\section{An Alternative Theory of PS Projection through Attitude Predicates}

We are now ready to develop a semantic analysis of attitude reports that involve deictic verbs. I adopt the view that an attitude (e.g. belief) is a relation between an individual and a propositional character (Schlenker 2003, Oshima 2006b). In a de $s e$ attitude report, the original attitude is "faithfully" reported, while in a non-de se report, the deictic (indexical) information in the original attitude is not maintained. To give a concrete example, the logical forms of the de se and non-de se reports (in Japanese) in (53a,b) can be roughly given as follows (the semantic contribution of the matrix/embedded tenses is left out of consideration).

a. John ${ }_{i}$-wa zibun ${ }_{i}$-ga yuumei-da to omotte-i-ru. John-Top self-Nom popular-be.Pres Comp believe-Asp-Pres ' $\mathrm{John}_{i}$ believes that he* ${ }_{i}$ is popular.' 
b. John $_{i}$-wa kare ${ }_{i}$-ga yuumei-da to omotte-i-ru.

John-Top he-Nom popular-be.Pres Comp believe-Asp-Pres

' $\mathrm{John}_{i}$ believes that he ${ }_{i}$ is popular.'

(53a) $\mapsto \lambda w_{1}\left[\exists e_{1}\right.$ [believe $\left(w_{1}, e_{1}\right.$, john, $\left.\left.\left.\lambda c_{1}\left[\lambda w_{2}\left[\exists e_{2}\left[\operatorname{popular}\left(w_{2}, e_{2}, \mathbf{A g}\left(c_{1}\right)\right)\right]\right]\right]\right)\right]\right]$

$(53 b) \mapsto \lambda w_{1}\left[\exists e_{1}\left[\exists \chi_{1}\langle c,\langle s, t\rangle\rangle\left[\exists r_{1}\left[\operatorname{believe}\left(w_{1}, e_{1}\right.\right.\right.\right.\right.$, john, $\left.\chi_{1}\right) \wedge$

$\chi_{1}\left(\left\langle\mathbf{j o h n}, \mathbf{T}-\operatorname{loc}\left(w_{1}, e_{1}\right), \mathbf{S}-\operatorname{loc}\left(w_{1}, e_{1}\right), r_{1}\right\rangle\right)=$

$\left.\left.\left.\left.\left.\lambda w_{2}\left[\exists e_{2}\left[\operatorname{popular}\left(w_{2}, e_{2}, x_{0}\right)\right]\right]\right]\right)\right]\right]\right]$

(N.B.) $r_{1}, r_{2}, r_{3}, \ldots$ are variables over RP's (sets of individuals).

In a de se report, the denotation of the complement clause is a propositional character, which directly corresponds to the object of the original attitude (for 53a, 'I am popular'). In a non-de se report, the denotation of the complement clause is a propositional content, which is "less fine-grained" than the object of the original attitude; from (53b), for example, we can infer only that the original belief corresponds to some propositional character $\chi_{1}$ such that when uttered by John, $\chi_{1}$ amounts to the propositional content 'John is popular' (and we cannot determine whether the original belief is 'I am popular' or 'John/he is popular'). ${ }^{10}$

One complication in this connection, however, is that in natural language we find attitude reports that are de se only with respect to a subset of the context coordinates (i.e., agent, addressee, time, place, RP, etc.). To give an example, the following report in Zazaki, which is adapted from Anand and Nevins (2004), is de $s e$ with respect to place (and possibly time), but not with respect to agent.

Waxto $\mathrm{ke}$ ma D.-de bime, $\mathrm{H}$. mi-ra va $\mathrm{ke}$ o ita ame dina. when that we D.-at were H.obv me-at said that he here came world

'When we were in Diyarbekir, Hesen told me he was born in D.'

In the following, for ease of presentation, I exclude indexicals other than deictic verbs from consideration, and assume (i) that attitude reports are either canonically de se (i.e. de se with respect to all context coordinates) or canonically non-de se (i.e. non-de se with respect to all context coordinates), and (ii) that (all) non-de se attitude predicates behave as "holes" (for presuppositions) and (all) de se attitude predicates behave as "filters". 11

\subsection{Attitude Predicates as Holes}

In a report where the deictic perspective is anchored to the primary agent (the external speaker), the presupposed/indexical part of the original attitude is underspecified; for instance, when "Bob believes that Chris came to San Jose" is interpreted

\footnotetext{
${ }^{10}$ The RP variable $r_{1}$ (and its binder) in (53b) is used merely as a "place holder", and does not contribute to the meaning of the whole sentence in any substantial way.

${ }^{11}$ See Oshima (2006b) for discussion of semantic treatments of "partially de se" attitude reports like (56).
} 
in the way that it (roughly) presupposes 'The speaker or the addressee (actually) is or was in San Jose', John's original belief could have been either 'Chris went to San Jose', 'Chris came to San Jose', or 'Chris moved to San Jose'. The assertion and presupposition of an attitude report with an attitude predicate that serves as a "hole" can be schematized as follows:

" $\alpha v$ 's $\phi$ ", where $v$ is a hole and $\phi$ denotes the propositional content $p_{1}$,

a. asserts: that $\alpha$ is related by the attitude relation denoted by $v$ with a propositional character $\chi$, such that $\chi(c)$ where $c$ is the context of $\alpha$ 's $v$-ing amounts to the propositional content $p_{2}$, such that the asserted part of $p_{2}$ is equivalent to the asserted part of $p_{1}$;

b. presupposes: the presupposed part of $p_{1}$.

The logical representation of an attitude verb like (58), where $p p$ stands for "primary perspective", brings out these effects:

$$
\begin{aligned}
& \operatorname{believe~}_{p p} \mapsto \\
& \lambda p_{1\langle s, t\rangle}\left[\lambda x \left[\lambda e _ { 1 } \left[\lambda w _ { 1 } \left[\left\langle\exists \chi _ { 1 } \left[\exists r _ { 1 } \left[\forall w _ { 2 } \left[\operatorname{Conv}_{1}\left(p_{1}\left(w_{2}\right)\right) \equiv\right.\right.\right.\right.\right.\right.\right.\right. \\
& \left.\operatorname{Conv}_{1}\left(\chi_{1}\left(\left\langle x, \mathbf{T}-\operatorname{loc}\left(w_{1}, e_{1}\right), \mathbf{S}-\operatorname{loc}\left(w_{1}, e_{1}\right), r_{1}\right\rangle\right)\left(w_{2}\right)\right)\right] \wedge \\
& \left.\left.\left.\left.\left.\left.\left.\operatorname{believe}\left(w_{1}, e_{1}, x, \chi_{1}\right)\right]\right] ; \operatorname{Conv}_{2}\left(p_{1}\left(w_{1}\right)\right)\right\rangle\right]\right]\right]\right]
\end{aligned}
$$

The derivation of an attitude report where a deictic predicate is anchored to the primary perspective is illustrated below. (61) guarantees that (59) (i) (roughly) presupposes that John (or the addressee) is or was in San Jose, and (ii) asserts that the character corresponding to Bob's original belief is such that it is equivalent to 'Chris came to San Jose' when presupposition and indexical information are ignored. ${ }^{12}$

(59) John: "Bob believes that Chris came to San Jose." (primary perspective) ps: John (or the addressee) is or was in San Jose.

(60) that Chris came to San Jose $\mapsto$

$\lambda w_{3}\left[\exists e_{2}\left[\left\langle\operatorname{move}-\mathbf{t o}\left(w_{3}, e_{2}\right.\right.\right.\right.$, chris, s.j. $) ; \exists y[y \in \mathbf{R P}(c *) \wedge$

$\left.\left.\left.\left.\exists e_{3}\left[\mathbf{a t}\left(w_{3}, e_{3}, y, \mathbf{s . j}.\right)\right]\right]\right\rangle\right]\right]$

(61) Bob believes Bp $_{p}$ that Chris came to San Jose $\mapsto$ $\lambda w_{1}\left[\exists e_{1}\left[\left\langle\exists \chi_{1}\left[\exists r_{1}\left[\forall w_{2}\left[\operatorname{Conv}_{1}\left(\exists e_{2}\left[\left\langle\operatorname{move-to}\left(w_{2}, e_{2}, \mathbf{c h r i s}, \mathbf{s . j} . \mathbf{j}\right) ;\right.\right.\right.\right.\right.\right.\right.\right.\right.$

$\left.\left.\left.\exists y\left[y \in \mathbf{R P}(c *) \wedge \exists e_{3}\left[\mathbf{a t}\left(w_{2}, e_{3}, y, \mathbf{s . j}.\right)\right]\right]\right\rangle\right]\right) \equiv$

$\left.\operatorname{Conv}_{1}\left(\chi_{1}\left(\left\langle x, \operatorname{T-loc}\left(w_{1}, e_{1}\right), \operatorname{S-loc}\left(w_{1}, e_{1}\right), r_{1}\right\rangle\right)\left(w_{2}\right)\right)\right] \wedge$

$\left.\left.\operatorname{believe}\left(w_{1}, e_{1}, \mathbf{b o b}, \chi_{1}\right)\right]\right] ; \operatorname{Conv}_{2}\left(\exists e_{2}\left[\left\langle\operatorname{move}-t o\left(w_{1}, e_{2}, \operatorname{chris}, \mathbf{s . j}.\right)\right.\right.\right.$; $\left.\left.\left.\left.\left.\left.\exists y\left[y \in \mathbf{R P}(c *) \wedge \exists e_{3}\left[\operatorname{at}\left(w_{1}, e_{3}, y, \mathbf{s . j}.\right)\right]\right]\right\rangle\right]\right)\right\rangle\right]\right]$

\footnotetext{
${ }^{12}$ In the derivation process, I assume that the lambda-bound event variable introduced by a predicate is (replaced by another variable that is) existentially bound at the VP or S node.
} 


\subsection{Attitude Predicates as Filters}

As mentioned earlier, attitude predicates can be "filters" too, which pass up the presupposition of their complement clause in a modified form (Karttunen 1974, Heim 1992):

" $\alpha$ v's $\phi$ ", where $v$ is a filter and $\phi$ denotes the propositional character $\chi$,

a. asserts: that $\alpha$ is related by the attitude relation denoted by $v$ with $\chi$;

b. presupposes: that $\alpha$ is related by the "believing" relation with the presupposed part of $\chi$.

The logical translation of an attitude predicate as a filter can be given as follows ( $s p$ stands for "secondary perspective"):

$$
\begin{aligned}
& \text { believe }_{s p} \mapsto \lambda \chi_{1}\left[\lambda x \left[\lambda e _ { 1 } \left[\lambda w _ { 1 } \left[\left\langle\operatorname{believe}\left(w_{1}, e_{1}, x, \chi_{1}\right) ;\right.\right.\right.\right.\right. \\
& \left.\left.\left.\left.\left.\exists e_{2}\left[\operatorname{believe}\left(w_{1}, e_{2}, x, \lambda c_{1}\left[\lambda w_{2}\left[\operatorname{Conv}_{2}\left(\chi_{1}\left(c_{1}\right)\left(w_{2}\right)\right)\right]\right]\right)\right]\right\rangle\right]\right]\right]\right]
\end{aligned}
$$

Let us consider the logical representation of an attitude report where the deictic perspective is anchored to the secondary perspective:

(64) John: "Bob believes that Chris came to San Jose." (secondary perspective)

ps: Bob believes that he is or was in San Jose.

Deictic verbs that are interpreted with respect to a secondary context can be understood as instances of secondary indexicals. For the sake of technical simplicity, I will take the view that deictic verbs (in languages like English and Japanese) are ambiguous between primary indexicals and secondary indexicals at the lexical level. The logical translations of $g o$ and come as secondary indexicals, which I mark with *, can be given as follows:

a. go* $\mapsto \lambda p l_{1}\left[\lambda x\left[\lambda e_{1}\left[\lambda w_{1}\left[\left\langle\operatorname{move}-\operatorname{to}\left(w_{1}, e_{1}, x, p l_{1}\right)\right.\right.\right.\right.\right.$;

$$
\left.\left.\left.\left.\left.\neg \exists y\left[y \in \mathbf{R P}\left(c_{1}\right) \wedge \exists e_{2}\left[\operatorname{at}\left(w_{1}, e_{2}, y, p l_{1}\right)\right]\right]\right\rangle\right]\right]\right]\right]
$$

b. come* $\mapsto \lambda p l_{1}\left[\lambda x\left[\lambda e_{1}\left[\lambda w_{1}\left[\left\langle\operatorname{move}-\operatorname{to}\left(w_{1}, e_{1}, x, p l_{1}\right)\right.\right.\right.\right.\right.$;

$$
\left.\left.\left.\left.\left.\exists y\left[y \in \mathbf{R P}\left(c_{1}\right) \wedge \exists e_{2}\left[\mathbf{a t}\left(w_{1}, e_{2}, y, p l_{1}\right)\right]\right]\right\rangle\right]\right]\right]\right]
$$

The derivation of the logical form of (64) is illustrated below. ${ }^{13}$

that Chris came* to San Jose $\mapsto$

$\lambda c_{2}\left[\lambda w_{3}\left[\exists e_{3}\left[\left\langle\mathbf{m o v e}-\mathbf{t o}\left(w_{3}, e_{3}\right.\right.\right.\right.\right.$, chris, s.j. $) ; \exists y\left[y \in \mathbf{R P}\left(c_{2}\right) \wedge\right.$

$\left.\left.\left.\left.\left.\exists e_{4}\left[\mathbf{a t}\left(w_{3}, e_{4}, y, \mathbf{s . j} \cdot \mathbf{0}\right)\right]\right]\right\rangle\right]\right]\right]$

(67) Bob believes $_{s p}$ that Chris came* to San Jose $\mapsto$

$\lambda w_{1}\left[\exists e_{1}\left[\left\langle\operatorname{believe}\left(w_{1}, e_{1}\right.\right.\right.\right.$, bob, $\lambda c_{2}\left[\lambda w_{3}\left[\exists e_{3}\left[\left\langle\operatorname{move-to}\left(w_{3}, e_{3}\right.\right.\right.\right.\right.$, chris, $\left.\mathbf{s . j}.\right) ;$

$\left.\left.\left.\left.\left.\exists y\left[y \in \mathbf{R P}\left(c_{2}\right) \wedge \exists e_{4}\left[\mathbf{a t}\left(w_{3}, e_{4}, y, \mathbf{s . j}.\right)\right]\right]\right\rangle\right]\right]\right]\right) ;$

$\exists e_{2}\left[\operatorname{believe}\left(w_{1}, e_{2}\right.\right.$, bob, $\lambda c_{1}\left[\lambda w_{2}\left[\operatorname{Conv}_{2}\left(\exists e_{3}\left[\left\langle\operatorname{move}-t o\left(w_{2}, e_{3}\right.\right.\right.\right.\right.\right.$, chris, s.j. $)$;

$\left.\left.\left.\left.\left.\left.\left.\left.\left.\left.\exists y\left[y \in \mathbf{R P}\left(c_{1}\right) \wedge \exists e_{4}\left[\mathbf{a t}\left(w_{2}, e_{4}, y, \mathbf{s . j}.\right)\right]\right]\right\rangle\right]\right)\right]\right]\right)\right]\right\rangle\right]\right]$

\footnotetext{
${ }^{13}$ I assume that the lambda operator that binds the context variable introduced by come $^{*}$ is introduced at the CP node.
} 
Note that (67) does not presuppose that Bob is or was in San Jose in actuality, but only in his belief. ${ }^{14}$

\section{Summary}

In this paper, I proposed that deictic verbs like go/come are instances of indexical expressions, and argued that the "deictic perspective shift" phenomenon in reported discourse can be given a straightforward account under this analysis. An attitude report from the primary deictic perspective is non-de se with respect to motion deixis, and a deictic verb occurring in (the complement clause of) such a report is a primary indexical. An attitude report from the secondary deictic perspective, on the other hand, is de se with respect to motion deixis, and a deictic verb occurring in (the complement clause of) such a report can be understood as a secondary indexical in the sense of Schlenker (2003). I further demonstrated that observations of attitude reports that involve deictic predicates lend support to the view that attitude predicates can be "holes" for presuppositions.

\section{References}

Anand, Pranav and Andrew Nevins: 2004, 'Shifty Operators in Changing Contexts', Semantics and Linguistic Theory 14.

Beaver, David and Henk Zeevat: 2004, 'Accommodation', in G. Ramchand and C. Reiss (eds.), Oxford Handbook of Linguistic Interfaces. Oxford University Press, Oxford.

Bergmann, Merrie: 1981, 'Presupposition and Two-dimensional Logic', Journal of Philosophical Logic 10, 27-53.

Blamey, Steven: 1986, 'Partial Logic', in D. Gabbay and F. Guenthner (eds.), Handbook of Philosophical Logic, Vol. 3, 1-70. Reidel, Dordrecht.

Blau, Ulrich: 1985, 'Die Logik der Unbestimmheiten und Paradoxien (Kurzfassung)', Erkenneus 22, 369-459.

Fillmore, Charles J.: 1997, Lectures on Deixis. CSLI Publications.

Heim, Irene: 1983, 'On the Projection Problem for Presuppositions', in M. Barlow, D. Flickinger, and M. Wescoat (eds.), Proceedings of WCCFL, Vol. 2, 114125. Stanford University.

\footnotetext{
${ }^{14}$ Sentences like the following, which would lead to unavailable interpretations, must be excluded with additional restrictions:

(i) a. Bob believes $s p$ that Chris came to San Jose. ( $s p$ attitude predicate/primary deictic predicate)

b. Bob believes ${ }_{p p}$ that Chris came* to San Jose. ( $p p$ attitude predicate/secondary deictic predicate)
}

See Oshima (2006b) for possible solutions. 
Heim, Irene: 1992, 'Presupposition Projection and the Semantics of Attitude Verbs', Journal of Semantics 9, 183-221.

Herzberger, Hans: 1973, 'Dimensions of Truth', Journal of Philosophical Logic 2 , 535-556.

Hockett, Charles F.: 1990, 'Bring, Take, Come and Go', Journal of English Linguistics 23, 239-244.

Karttunen, Lauri: 1974, 'Presupposition and Linguistic Context', Theoretical Linguistics 1, 181-194.

Karttunen, Lauri and Stanley Peters: 1979, 'Conventional Implicature', in C.-K. Oh and D. A. Dinneen (eds.), Presupposition (Syntax and Semantics 11), 1-56. Academic Press, New York.

Kuno, Susumu: 1988, 'Blended Quasi-direct Discourse in Japanese', in W. J. Poser (ed.), Papers from the Second International Workshop on Japanese Syntax, 75-102. CSLI Publications, Stanford.

Oe, Saburo: 1975, Nichieigo no hikakukenkyû: syukansei o megutte [A Comparative Study of Japanese and English: On Subjectivity]. Nanundo, Tokyo.

Oshima, David Y.: 2006a, 'GO and COME Revisited: What Serves as a Reference Point?', in Proceedings of the 32nd Berkeley Linguistics Society.

Oshima, David Y.: 2006b, Perspectives in Reported Discourse, Doctoral dissertation, Stanford University.

van der Sandt, Rob and Bart Geurts: 2001, 'Too', in Proceedings of the 13th Amsterdam Colloquium, 180-185.

Schlenker, Philippe: 2003, 'A Plea for Monsters', Linguistics and Philosophy 26, 29-120.

Talmy, Leonard: 2000, Toward a Cognitive Semantics vol.2: Typology and Process in Concept Structuring. The MIT Press, Cambridge, MA.

Zeevat, Hank: 1992, 'Presupposition and Accommodation in Update Semantics', Journal of Semantics 9, 379-412. 